\title{
Determination Model of Tectonic Seismicity Level In Earthquake Early Warning System By Implementing ANFIS (Adaptive Neuro Fuzzy Inference Systems)
}

\author{
Setyawan, D. ${ }^{1}$, Yuliawati, D ${ }^{2}$, Warsito ${ }^{3}$, Warsono ${ }^{4}$ \\ \{dodi@darmajaya.ac.id ${ }^{1}$, donayuliawati@gmail.com ${ }^{2}$,warsito@fmipa.unila.ac.id ${ }^{3}$, \\ warsono@fmipa.unila.ac.id $\left.{ }^{4}\right\}$
}

Computer System Department IIB Darmajaya Lampung, Indonesia ${ }^{1}$, Information System Department IIB Darmajaya Lampung, Indonesia ${ }^{2}$, Physic Department Faculty of Mathematics and Natural Sciences Lampung University Lampung, Indonesia ${ }^{3}$, Mathematics Department Faculty of Mathematics and Natural Sciences Lampung, Indonesia ${ }^{4}$

\begin{abstract}
Determination Model of tectonic seismicity level using ANFIS method in the real time earthquake early warning system will be described in this research. the system is based on the data from monitoring tectonic activities using flux magnet sensor, ground temperature sensor and Radio Frequency. The system learning uses recursive square estimator algorithm (RSQ) and backpropagation gradient descent. It results in an error value of 1.1527 for epoch 100 in the training process. Whereas, the test process results in an error value of 1.1527 and in outline that the result of determination with ANFIS is close to the actual value of the seismicity level.
\end{abstract}

Keywords: ANFIS, earthquake.

\section{Introduction}

An earthquake is a natural phenomenon of the earth, where the earthquakes that occur is a characteristic of the earth to maintain stability. In other words, earth disaster events must occur. The earth, though solid, always moves, and earthquakes occur when the pressure that occurs because the movement is too big to bear. Most earthquakes are caused by the release of energy generated by the pressure made by moving plates. The longer the pressure becomes larger and ultimately reaches a state where the pressure cannot be retained by the plate edges. That is when an earthquake will occur. Earthquakes usually occur on the border of the plate. The most severe earthquakes usually occur at the border of compressional and translational plates. Earthquakes cause a lot of casualties and property that is not small in number. The earthquakes of Aceh, the Medan earthquake, the Padang earthquake, the Jogjakarta earthquake and other earthquakes in various parts of Indonesia and the world should have motivated researchers to be more concerned about earthquake researches, especially the development of the earthquake early warning system. Some of the early signs or symptoms of an earthquake are the phenomena of Total Electron Content in the ionospheric layer.[1][2][3] Due to the movement of the plates, fractures affect the gravity and magnetic minerals in the earth,

ICCSET 2018, October 25-26, Kudus, Indonesia

Copyright (c) 2018 EAI

DOI 10.4108/eai.24-10-2018.2280617 
disturbing the stability of the electromagnetic force. These symptoms can be sensed by firing radio frequency modulation waves from the transmitting station and retrieving the data at the receiving station. The data read on the receiving station is the amplitude of Radio Frequency (RF) and Audio Frequency amplitude (AF) or nois. The higher Electron Content available in the ionosphere layer, the higher Radio Frequency data value will be and the lower the Audio frequency will be. Conversely the lower the Electron Content, the lower the data value of the Radio Frequency will be and the higher the Audio Frequency or nois will be. This disturbance can be up to a radius of 400 kilometers above the earth's surface in the ionosphere layer and increased geomagnetism on the earth's surface within a certain time before the earthquake[4] and geomagnetism can be censored using fluxgate magnetometer sensors. Besides, the seismic forces can be measured using conventional seismographs and Seismograph-Based Optics.

From the literature study above, it can be made a model of earthquake early warning system to determine the level of earthquake strength by implementing ANFIS. The sensors used include fluxgate magnetometer sensor, ground temperature sensor, FM receiver and optical-based seismograph. the data acquisition analysis for multiple sensors using modulation frequency with telemetry technique can be done. [5]In addition, ANFIS is also widely used in various researches, such as the use of ANFIS for the stability of single machine power output [6] and multi engine [7], broiler cage temperature setting [8], color clashing on ancient inscriptions [9], for Short-Term Load Forecasting [10], Evaluation of Flashover Voltage Levels of Contaminated Hydrophobic Polymer Insulators [11], for determination of PH value [12], to detect breast cancer[13], determination of river flow direction [14], Optimization of the Production of Inactivated Clostridium novyi Type B Vaccine [15], Quantitative StructureActivity Relationship Model for HCVNS5B inhibitors based on an Antlion [16] determination of forecasting volcanic eruption [17], density prediction for long term wind power [18], prediction water quality index of Satluj river in India [19]. To predict the seismic strength level cannot be predicted certainty by stochastic method. To optimize the earthquake power level determination ANFIS is used. It is hoped that this research will get an accurate tectonic earthquake early warning model..

\section{Methode}

The combination of two systems namely fuzzy logic system and neural network is called Neuro-fuzzy. Learning algorithms derived from artificial neural network systems can be used to train fuzzy inference systems. Neuro fuzzy has advantages possessed by fuzzy inference system and artificial neural network system. ANFIS has the ability to learn. The shape of the ANFIS structure can be seen in figure 1. This system uses the Tagaki-Sugeno-Kang model fuzzy inference. 


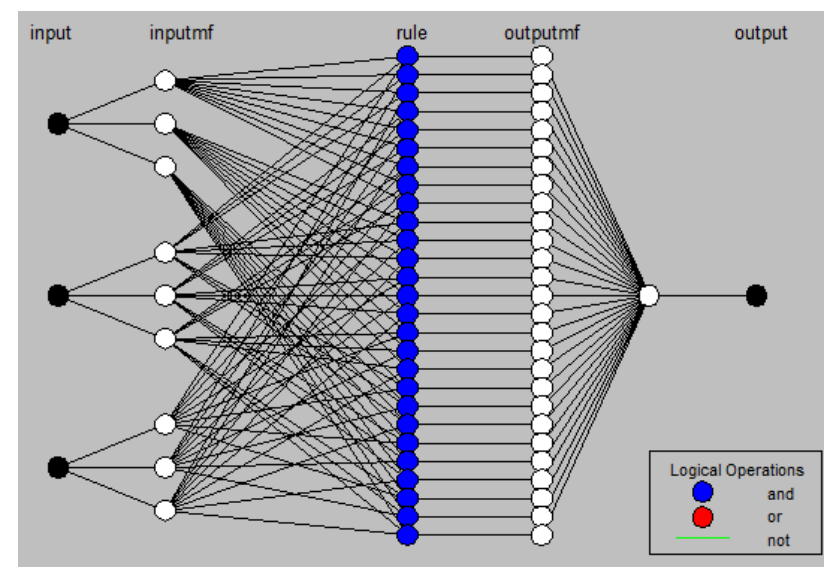

Fig. 1. ANFIS Structure.

Functions and the five-layer equations that neuro fuzzy systems have can be explained as follows:

a) Layer 1 : Fuzzyfication Layer

$\mathrm{O}_{1, \mathrm{i}}$ becomes the output for every node at layer 1 . Every node $\mathrm{i}$ at this node is an adaptive node with the function of $\mathrm{O} 1, \mathrm{i}=\mu \mathrm{Ai}(\mathrm{x})$ for $\mathrm{i}=1,2$; or $\mathrm{O} 1, \mathrm{i}=\mu \mathrm{Bi}(\mathrm{y})$ for $\mathrm{i}=$ 1,2 , where $\mathrm{x}$ is an input to node $\mathrm{i}$ and $\mathrm{Ai}$ is a linguistic label (small, medium, large) which corresponds to the function of this node. In another side O1, i is the membership function of $\mathrm{A} 1$ and the degree of membership is specific for giving $\mathrm{x}$ for the adequacy of the Ai quantization. . The most widely used membership functions are Bells and Gaussian forms. Bell Membership function is expressed by:

$$
f\left(x_{x} a_{x}, b_{x} c\right)=\frac{1}{1+\left[\frac{x-c}{a}\right]^{215}}
$$

With the following conditions:

Parameter $\mathrm{b}$ is positive

Parameter $\mathrm{c}$ is in the middle of the curve

While the Gaussian equation is expressed as follows:

$$
A(x)=e^{\frac{(x-6)^{2}}{2 a^{2}}}
$$

b) Layer 2 : Product Layer

Transmitting information with layer 1 and multiplication of all incoming signals and outgoing products synthesized on this layer 2 . Each node in this layer consists of a tnorm product operator as a node function. The output of this layer is expressed by the following equation:

$$
Q_{2,1}=W_{1}=\mu A_{i}(X) \cdot \mu B_{i}(y)
$$


The power size of the rules is served at every node in this layer. The output of this layer is used as a weight function.

c) Layer 3: Normalization Layers

The weight function obtained from layer 2 will be normalized in layer 3 . The normalization equation is as follows:

$$
O_{\mathrm{a}_{\mathrm{i}} \mathrm{i}}=\frac{\mathrm{W}_{\mathrm{f}}}{W_{2}+W_{2}}
$$

d) Layer 4 : Defuzzification Layer

The output of this layer which is a natural adaptive is expressed by the equation:

$$
O_{4 i}=O_{a, 1}\left(\alpha_{i} x+\beta_{i} y+\gamma_{i}\right)
$$

e) Layer 5 : Total Output Layer

The information transmitted in layer 4 will be synthesized in a single layer 5 . The output of this layer is expressed by the following equation:

$$
O_{5, i}=\frac{\sum w_{1}\left(a_{1} x+\beta_{1} y+W_{i}\right)}{\sum w_{1}}
$$

The ANFIS learning process is found in the adaptive nodes found in the first and fourth layers. The nonlinear premise parameter is attached to the first node while the linear consequent parameters are in the fourth layer. It needs an algorithm to update the parameters in the learning process. Learning methods are many kinds, such as hybrid learning algorithm. Input data, ANFIS parameter and data test is data used for learning process. This hybrid learning consists of two sections namely forward and backward directions. ANFIS learning process can be seen in table 1 below

Table 1. ANFIS learning process.

\begin{tabular}{lll}
\hline & Directions Backward & Directions Forward \\
\hline premise parameters & EBP & Fixed \\
Consequent Parameters & Fixed & LSE \\
Signal & Signal Error & Node Output \\
\hline
\end{tabular}

The membership function of the fuzzy set is nonlinear to the system output is a parameter in layer one. In this layer use EBP to affect parameter values. The linear parameter to the system output is the fourth layer parameter that constructs the fuzzy rules. This learning process will affect the parameters and methods used in this layer is called the LSE (Last Squares Estimator) method

The secondary data used are magnetic fluxgate sensor output data, ground temperature sensor, radio frequency and optical-based seismograph. The data is physical quantity of temperature with unit of Celsius degree, geomagnetism physical data value with unit of mikrotesla, data of decimal conversion value of physical quantity of frequency radio nois level and conversion data of physical quantity of earthquake strength with unit or Richter scale. The data obtained is divided into two parts, the first part is used as training data and the second data is used as test data. The research flow is carried out as follows: 


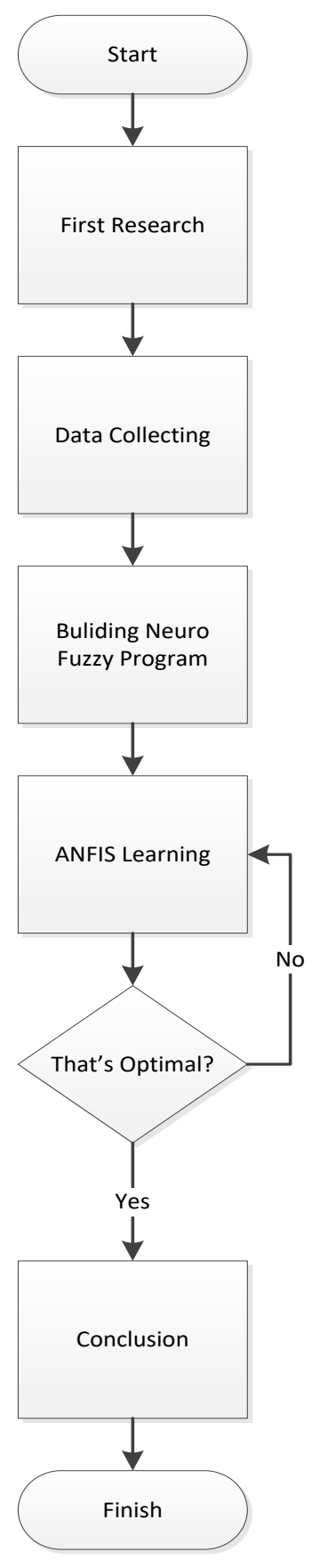

Fig. 2. The research flow.

The secondary data used for the training process is the data of the previous research results which each sensor has been calibrated. 
Table 2. secondary data[20]

\begin{tabular}{|c|c|c|c|c|c|}
\hline \multicolumn{3}{|c|}{$\begin{array}{c}\text { Fluxmagnet }(\mathrm{x}, \mathrm{y}, \mathrm{z} \\
\text { dimension) }\end{array}$} & \multirow[t]{2}{*}{ Soil temperature } & \multirow[t]{2}{*}{ Radio frequency } & \multirow{2}{*}{$\begin{array}{c}\text { The degree of } \\
\text { seismicity } \\
\text { (Optical seismograph }\end{array}$} \\
\hline $\mathrm{x}$ & $\mathrm{y}$ & $\mathrm{z}$ & & & \\
\hline 1293 & 451 & 362 & 25 & 454 & 1 \\
\hline 1283 & 456 & 365 & 25 & 459 & 2 \\
\hline 1273 & 457 & 365 & 25 & 460 & 3 \\
\hline 1284 & 456 & 367 & 25 & 459 & 1 \\
\hline 1291 & 457 & 367 & 25 & 460 & 3 \\
\hline 1290 & 457 & 368 & 25 & 460 & 1 \\
\hline 1290 & 457 & 362 & 25 & 460 & 2 \\
\hline 1290 & 457 & 364 & 25 & 460 & 1 \\
\hline 1287 & 457 & 364 & 25 & 460 & 1 \\
\hline 1286 & 457 & 364 & 25 & 460 & 2 \\
\hline 1293 & 451 & 362 & 26 & 454 & 1 \\
\hline 1283 & 456 & 365 & 26 & 459 & 2 \\
\hline 1273 & 457 & 365 & 26 & 460 & 1 \\
\hline 1284 & 456 & 367 & 26 & 459 & 2 \\
\hline 1291 & 457 & 367 & 26 & 460 & 3 \\
\hline 1290 & 457 & 368 & 26 & 460 & 1 \\
\hline 1290 & 457 & 362 & 26 & 460 & 2 \\
\hline 1290 & 457 & 364 & 26 & 460 & 1 \\
\hline 1287 & 457 & 364 & 26 & 460 & 3 \\
\hline 1286 & 457 & 364 & 26 & 460 & 1 \\
\hline 1293 & 455 & 362 & 26 & 458 & 1 \\
\hline 1283 & 456 & 365 & 26 & 459 & 1 \\
\hline 1273 & 457 & 365 & 26 & 460 & 1 \\
\hline 1284 & 456 & 367 & 26 & 459 & 1 \\
\hline 1291 & 457 & 367 & 26 & 460 & 1 \\
\hline 1290 & 457 & 368 & 26 & 460 & 1 \\
\hline 1290 & 457 & 362 & 26 & 460 & 9 \\
\hline 1290 & 457 & 364 & 26 & 460 & 7 \\
\hline 1287 & 457 & 364 & 26 & 460 & 8 \\
\hline 1286 & 457 & 364 & 26 & 460 & 5 \\
\hline 1293 & 454 & 362 & 27 & 457 & 4 \\
\hline 1283 & 456 & 365 & 27 & 459 & 3 \\
\hline 1273 & 457 & 365 & 27 & 460 & 2 \\
\hline 1284 & 456 & 367 & 27 & 459 & 1 \\
\hline 1291 & 457 & 367 & 27 & 460 & 2 \\
\hline 1290 & 457 & 368 & 27 & 460 & 1 \\
\hline 1290 & 457 & 362 & 27 & 460 & 2 \\
\hline 1290 & 457 & 364 & 27 & 460 & 2 \\
\hline 1287 & 457 & 364 & 27 & 460 & 5 \\
\hline 1286 & 457 & 364 & 27 & 460 & 6 \\
\hline 1293 & 454 & 362 & 24 & 457 & 4 \\
\hline 1283 & 456 & 365 & 24 & 459 & 3 \\
\hline 1273 & 457 & 365 & 24 & 460 & 2 \\
\hline 1284 & 456 & 367 & 24 & 459 & 2 \\
\hline 1291 & 457 & 367 & 24 & 460 & 1 \\
\hline 1290 & 457 & 368 & 24 & 460 & 2 \\
\hline 1290 & 457 & 362 & 24 & 460 & 4 \\
\hline
\end{tabular}




\begin{tabular}{cccccc}
\hline \multicolumn{2}{c}{$\begin{array}{c}\text { Fluxmagnet }(\mathrm{x}, \mathrm{y}, \mathrm{z} \\
\text { dimension) }\end{array}$} & Soil temperature & Radio frequency & $\begin{array}{c}\text { The degree of } \\
\text { seismicity } \\
\text { (Optical seismograph) }\end{array}$ \\
\hline \multicolumn{2}{c}{$\mathrm{y}$} & $\mathrm{z}$ & & & 5 \\
\hline 1290 & 457 & 364 & 24 & 460 & 3 \\
1287 & 457 & 364 & 24 & 460 & 2 \\
1286 & 457 & 364 & 24 & 460 & \\
\hline
\end{tabular}

After the program is completed then tested to get the error value of epoch given. The next step is conclusion. In the development phase of the program will be training using ANFIS to determine parameters, in the IF, parameters $\mathrm{a}, \mathrm{b}$ and $\mathrm{c}$ (premise parameters) and parameters on the THEN (consequent parameters). The error values obtained from these parameters can be used for the next step. Clustering stage to determine the incoming data to a cluster. After that determine the mean and deviation values on each cluster. The output in the first layer is the degree of membership of each data. In the third layer is normalized. In the fourth stage determine the consequent parameters. In the fifth stage do the sum with the fourth layer. In a step forward, a recursive Least squares estimator is used to improve the value of consequent parameters until a small error value is obtained. While in step back use propagation error to improve the value of premise parameter. Next calculate the error value of network output.

\section{Results and Discussion}

With the value of epoch 100 will get an error value of 1.1527 shown in Figure 2 as follows

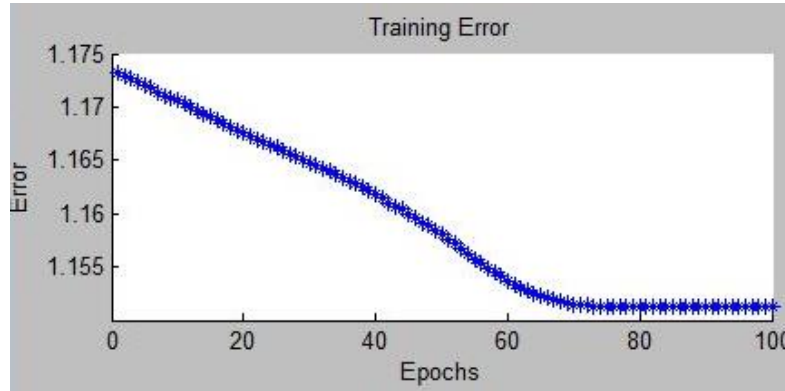

Fig. 3. Training.

The comparison graph of training between seismic strength level status and ANFIS result is close to the actual status of tectonic earthquake strength level. The comparison graph is shown below: 


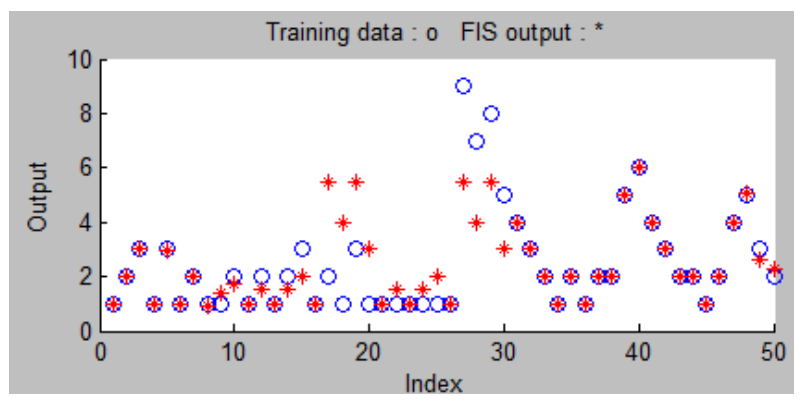

Fig. 4. Result of Comparison Process.

The results of the training process are then used in the testing process, the error value of the test process results of 1.1527 . The comparison graph of the comparison result between the status of the degree of tectonic seismicity and ANFIS shown in Figure 4

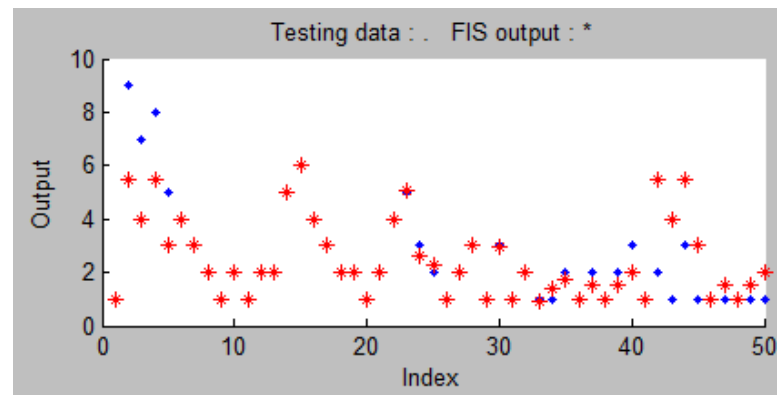

Fig. 5. Result of Testing Process.

From the testing comparison graph between the actual status of tectonic seismicity level and the ANFIS test result it can be seen that the outline of determination result with ANFIS is close to actual value.

\section{Conclusion}

Based on the discussion of the neuro fuzzy model the ANFIS model is applied for the determination of tectonic seismicity level resulted in an error value of 1.1527 for epoch 100 on the training process. While the test process results in an error value of 1.1527 and in outline that the results of determination with ANFIS is close to the actual value of tectonic seismicity.

\section{Reference}

[1] Fumumoto, Hayakawa, and H. Yasuda, "Investigation of over-horizon VHF radio signals associated with earthquakes," Nat. Hazards Earth Syst. Sci. 1.3, pp. 107-112, 2001.

[2] Jain, S. Kumar, G. Panda, and S. Vijay, "Study of variation in slab thickness of ionospheric Fregion during earthquake by wavelet analysis," Indian J. Phys. 84.4, pp. 359-365, 2010.

[3] L. F and M. Parrot, "Total electron content variations observed by a DORIS station during the 2004 Sumatra-Andaman earthquake,” J. Geod. 80.8-11, pp. 487-495, 2006. 
[4] Kozak, Jan, and A. Plešinger, "Beginnings of regular seismic service and research in the AustroHungarian Monarchy: Part I," Stud. Geophys. Geod. 47.1, pp. 99-119, 2003.

[5] Warsito, S. Suciyati Wahyu, and Jhonizar, "Analysis of Data Acquisition from Multisensors Using A 0.11 GHz Frequency Modulation Telemetry,” Eur. J. Sci. Res., vol. 49, 2011.

[6] Ginarsa, i Made, and O. Zebua, "Stability improvement of single machine using ANFIS-PSS based on feedback-linearization," TELKOMNIKA (Telecommunication Comput. Electron. Control. 12.2, pp. 315-324, 2014.

[7] Muljono, A. Budi, and I Made Ari Nrartha, "Dynamic Stability Improvement of Multimachine Power Systems using ANFIS-based Power System Stabilizer," TELKOMNIKA (Telecommunication Comput. Electron. Control., pp. 1170-1178, 2015.

[8] Alimuddin and et al, "Temperature Control System in Closed House for Broilers Based on ANFIS,” TELKOMNIKA (Telecommunication Comput. Electron. Control. 10.1, pp. 75-82, 2012.

[9] Rasmana, T. Susijanto, K. Yoyon, K. Suprapto, and K. E. Purnama, "Color clustering in the metal inscription images using ANFIS filter," TELKOMNIKA (Telecommunication Comput. Electron. Control. 11.3, pp. 529-536, 2013.

[10] Mustapha, Mamunu, M. W. Mustafa, and Saiful Nizam Abd Khalid, "Data selection and fuzzyrules generation for short-term load forecasting using ANFIS," TELKOMNIKA (Telecommunication Comput. Electron. Control. 14.3, pp. 791-799, 2016.

[11] Abo-Elyousr, K. Farag, and L. . Nassrat, "Evaluation of Flashover Voltage Levels of Contaminated Hydrophobic Polymer Insulators Using Regression Trees, Neural Networks, and Adaptive Neuro-Fuzzy,” TELKOMNIKA 16.2, pp. 495-512, 2018.

[12] Yasmin, N. S. Ahmad, and E. Al, "Estimation of pH and MLSS using Neural Network," Telkomnika 15.2, 2017.

[13] Übeyli and E. Derya, "Adaptive neuro-fuzzy inference systems for automatic detection of breast cancer,” J. Med. Syst. 33.5, p. 353, 2009.

[14] Sanikhani, Hadi, and O. Kisi, "River flow estimation and forecasting by using two different adaptive neuro-fuzzy approaches,” Water Resour. Manag. 26.6, pp. 1715-1729, 2012.

[15] Aquino, P. L. M., and E. Al, "Optimization of the Production of Inactivated Clostridium novyi Type B Vaccine Using Computational Intelligence Techniques,” Appl. Biochem. Biotechnol. 179.5, p. 895-909., 2016.

[16] Elaziz, Mohamed Abd, and E. Al, "Quantitative Structure-Activity Relationship Model for HCVNS5B inhibitors based on an Antlion Optimizer-Adaptive Neuro-Fuzzy Inference System," Sci. reports 8.1, p. 1506, 2018.

[17] R. S. J. Sparks, "Forecasting volcanic eruptions," Earth Planet. Sci. Lett. 210.1-2, pp. 1-15, 2003.

[18] Hossain, Monowar, and et al, "Application of the hybrid ANFIS models for long term wind power density prediction with extrapolation capability," PloS one 13.4, 2018.

[19] Tiwari, Sharad, Richa Babbar, and G. Kaur, "Performance Evaluation of Two ANFIS Models for Predicting Water Quality Index of River Satluj (India),” Adv. Civ. Eng. 2018, 2018.

[20] Setyawan and Dodi Yudo, "Calibration of geomagnetic and soil temperatur Sensor for Earthquake Early Warning System," TELKOMNIKA (Telecommunication Comput. Electron. Control. 16.5, 2018. 